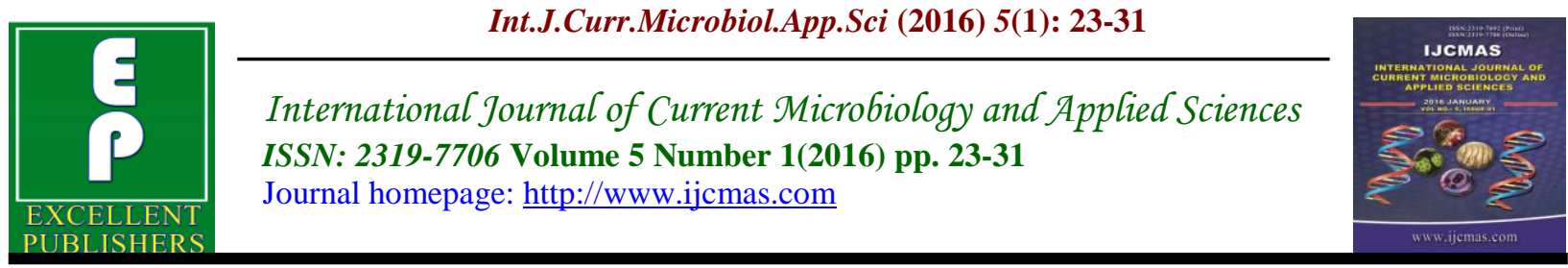

Original Research Article doi: http://dx.doi.org/10.20546/ijcmas.2016.501.003

\title{
Uropathogens and their Antibiotic Susceptibility Pattern at a Tertiary Care Teaching Hospital in Coastal Karnataka, India
}

\author{
P. Preethishree*, Rekha Rai, K. Vimal Kumar, K.B. Asha Pai and U. Pratibha Bhat \\ Department of Microbiology, K.S. Hegde Medical Academy, \\ Mangaluru-575018, Karanataka, India \\ *Corresponding author
}

\begin{abstract}
A B S T R A C T
Keywords

UTI,

Uropathogens, Escherichia coli, ESBL, Antibiotic susceptibility pattern.

\section{Article Info}

Accepted: 06 December 2015 Available Online: 10, January 2016

Urinary tract infections are common, easily diagnosed conditions with established laboratory methods of evaluation. Escherichia coli is by far the most common pathogen, accounting for about $80 \%$ of culture positive urinary tract infections. This study was undertaken to know the prevalence and antibiogram of uropathogens in our hospital. A total of 2191 clean catch midstream urine samples were processed in clinical microbiology laboratory during the study period. Uropathogens were identified by standard techniques and antibiotic sensitivity testing was carried out by Kirby Bauer Disk Diffusion method as per CLSI guidelines. Male to female ratio was 1:1.06. Escherichia coli was the predominant isolate accounting for $57.14 \%$ followed by Klebsiella species (17.62\%), Enterococcus species (8.1\%), Pseudomonas aeruginosa (6.98\%), Staphylococcus species (3.97\%). $64.44 \%$ of E.coli and $53.15 \%$ of Klebsiella produced ESBL. E.coli was highly sensitive to Amikacin $(89.17 \%$ ) and Nitrofurantoin $(85.83 \%)$. Our study showed a high prevalence of UTI in females and in the elderly patients. Most of the gram negative bacilli showed increasing rates of resistance Cephalosporins, Fluoroquinolones and Trimethoprim-sulfamethoxazole. The resistance pattern is on the rise indicating the need to establish antibiotic policies and take stringent measures to ensure effectiveness of the same.
\end{abstract}

\section{Introduction}

Urinary tract infections (UTIs) are the most common bacterial infections in humans showing increasing trends in spite of availability and use of antibiotic agents, in all age groups and both genders (Orhue 2014, Shah et al., 2015). It is the most common site for nosocomial infection. $3.2 \%$ of catheterised patients have UTI, even with adequate aseptic precautions during

instrumentation. 50\% of the patients with indwelling catheters have UTI with multidrug resistant bacteria (Ananthanarayan and Paniker, 2009). UTI following instrumentation is a frequent cause of significant morbidity, sepsis and death (Kulkarni et al., 2014). A variety of organisms can cause UTI including bacteria, fungi and viruses; bacteria being responsible for $95 \%$ of the cases. Most common 
etiological agents are Escherichia coli, Klebsiella species, Pseudomonas aeruginosa, Proteus mirabilis, Acinetobacter species, Enterococcus species and Staphylococcus species (Orhue, 2014). Treatment of UTI is often empiric and the extensive and inappropriate use of antibiotics has resulted in the emergence of multi drug resistant bacteria which is a major problem worldwide. Knowledge of the etiological agents of UTI and their antibiotic susceptibility pattern is necessary for ensuring appropriate treatment (Shah $e t$ al., 2015).

This study was undertaken to know the prevalence of uropathogens in our hospital and their antibiogram.

\section{Materials and Methods}

The study was conducted in the Department of Microbiology, of a tertiary care teaching hospital. A retrospective analysis was made on urine culture and sensitivity between January 2013 and October 2013. A total of 2191 clean catch midstream urine samples collected in a wide mouthed sterile container were received in the clinical microbiology laboratory. They were further processed by standard loop method (a semi quantitative method) and inoculated onto Blood agar, MacConkey agar and Cysteine Lactose Electrolyte Deficient agar. The plates were incubated aerobically at $37^{\circ} \mathrm{C}$ for $18-24$ hours. A wet mount preparation was analyzed for the presence of pus cells. Positive urine culture was determined by significant bacteriuria i.e., isolation of one or two pathogens (but not more than two) with $>10^{5}$ colony forming units per $\mathrm{ml}$ and presence of pyuria ( $>6$ pus cells per high power field). The organisms isolated were identified by their colony morphology, Gram Stain and relevant standard biochemical reactions (Collee et al.,).
Antibiotic susceptibility testing was carried out by Kirby Bauer Disk Diffusion method. A lawn culture was made on Mueller Hinton Agar and following antibiotic disks were tested: CPM-Cefipime $(30 \mu \mathrm{g}), \quad$ CTXCefotaxime $\quad(30 \mu \mathrm{g}), \quad$ CTR-Ceftriaxone $(30 \mu \mathrm{g}), \quad$ CAZ-Ceftazidime $(30 \mu \mathrm{g}), \quad$ PITPiperacillin- tazobactam $(100 / 10 \mu \mathrm{g})$, PIPiperacillin $(100 \mu \mathrm{g})$, AK-Amikacin $(30 \mu \mathrm{g})$, GEN-Gentamicin $(10 \mu \mathrm{g})$, TOB-Tobramycin $(10 \mu \mathrm{g}), \quad$ CIP-Ciprofloxacin $(5 \mu \mathrm{g}), \quad \mathrm{NX}-$

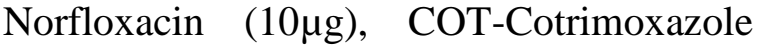
$(1.25 / 23.75 \mu \mathrm{g}), \quad$ NIT-Nitrofurantoin $(300 \mu \mathrm{g}), \quad$ IMP-Imipenem $(10 \mu \mathrm{g}), \quad$ TE-

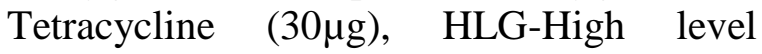

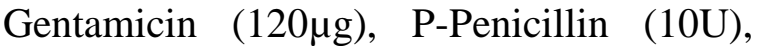
AMP-Ampicillin $\quad(10 \mu \mathrm{g}), \mathrm{CX}-\mathrm{Cefoxitin}$ $(30 \mu \mathrm{g})$, LZ-Linezolid $(30 \mu \mathrm{g}), \quad$ VAVancomycin $(30 \mu \mathrm{g})$. The plates were incubated aerobically at $37^{\circ} \mathrm{C}$ for $18-24$ hours. Zone sizes were measured and the drugs were interpreted to be sensitive or resistant according to CLSI guidelines (2013). Following drugs were tested for yeast isolates: Amphotericin B, Nystatin, Clotrimazole, Fluconazole, Ketoconazole. Antifungal susceptibility testing was carried out on Mueller Hinton Agar with Methylene blue.

\section{Results and Discussion}

A total of 2191 urine samples were received by the clinical microbiology laboratory during the period of study. Among these, 630 patients showed significant bacteriuria while 36 patients showed infection with yeast. DISCUSSION

Figure 1 shows gender distribution. There were 322 males and 344 females in our study accounting for $48.35 \%$ and $51.65 \%$ respectively. Male to female ratio was 1:1.06. Sharma et al. (2011) have reported male to female ratio of $1: 1.8$ and Orhue (2014) reported a ratio of 1:1.6. Razak et al. 
(2012) and Shah et al. (2015) have also observed female predominance in their studies. This finding of increased number of UTI in female sex can be attributed to the presence of short urethra in them.

Figure 2 and Table 1 show age distribution. UTI can occur at any age. Our study showed an increased rate of infection among patients of the age group of 41-70 years. Most of the cases belonged to the age group of 50-79 years $(57.4 \%)$ in a study by Eshwarappa et al. (2011) and 21-40 years (54.98\%) in a study by Razak et al. (2012).

Figure $3 \& 4$, Table 2 show distribution of the causative agents. In the present study we isolated 630 bacteria and 36 yeasts. Among the bacterial profile of UTI, Escherichia coli was the predominant isolate accounting for $57.14 \%$ followed by Klebsiella species (17.62\%), Enterococcus species (8.1\%), Pseudomonas aeruginosa (6.98\%), Staphylococcus $\quad$ species (3.97\%), Acinetobacter species (3.17\%), Citrobacter species $(1.11 \%)$, Enterobacter aerogenes $(0.95 \%)$, Proteus mirabilis $(0.79 \%)$ and Morganella morganii $(0.001 \%)$. Among 25 Staphylococcal species isolated 19 were S.aureus. Out of the 7 Citrobacter species isolated, 4 were C.freundii and 3 were C.koseri.

Eshwarappa et al. (2015), Shah et al. (2015), Hussein NS (2014) and Razak et al. (2012) have reported E.coli as the most commonly isolated bacteria in their study of UTIs, accounting for $66.9 \%, 61.02 \%, 39 \%$ and $37.95 \%$ respectively. Alemu et al. (2012) in their study of UTI in pregnant women also found E.coli as the most common causative agent $(47.5 \%)$. E.coli was the predominant isolate in various studies of UTIs in diabetic patients by Ampaire et al. (2015), Janifer et al. (2015) and Sibi et al. (2011); the percentage of isolation being $50 \%, 43.36 \%$ and $39.4 \%$ respectively. UTI studies on paediatric patients by Sharma et al. (2011) and Patel P et al. (2014) revealed that E.coli caused majority of the infections $(67.5 \%$ and $38.42 \%$ respectively).

Klebsiella species was the second most common organism isolated in our study $(17.62 \%)$. Similar finding has been reported by Shah et al. (2015), Eshwarappa et al. (2015), Razak et al. (2012) and Patel P et al. (2014); percentage of isolation being $13.56 \%, 15.5 \%, 21.41 \%$ and $23.89 \%$ respectively.

Pseudomonas and Proteus species are mostly associated with hospital acquired UTIs rather than community acquired UTIs. In our study Pseudomonas has been isolated from 44 samples accounting for $6.98 \%$ of bacterial isolates. Similar results have been observed by Shah et al. (2015) and Patel P et al. (2014). However, isolation rates of $10.2 \%$ and $2 \%$ have been reported by Eshwarappa et al. (2015) and Hussein NS (2014). Pseudomonas was the third common organism isolated in a study of catheter associated UTI by Kulkarni et al. (2014) accounting for $14.1 \%$.

A total of 36 yeasts were grown from the urine samples accounting for $5.41 \%$ of total isolates. 15 among them were Candida albicans (41.67\%). Razak et al. (2012) have reported $7.79 \%$ yeast isolates in their study.

Tables 3, 4, 5 and 6 show the antibiotic sensitivity pattern of bacterial isolates. E.coli was highly sensitive to Amikacin $(89.17 \%)$ and Nitrofurantoin $(85.83 \%)$ moderately sensitive to Piperacillintazobactam $(78.33 \%)$ and Least sensitive was to Ceftazidime (37.78\%), Ceftriaxone (35.56\%), Cefotaxime (35.56\%), Cefipime (39.44\%), Ciprofloxacin (28.33\%), Norfloxacin $(27.5 \%)$ and Cotrimoxazole 
(38.06\%). Similar sensitivity pattern has been reported by Shah et al. (2015), Razak et al. (2012) and Hussein NS (2014). $64.44 \%$ of E.coli produced Extended Spectrum Beta Lactamase.

Klebsiella species was highly sensitive to Amikacin (76.58\%) followed by Piperacillin-tazobactam (66.67\%), Gentamicin (57.66\%), Ciprofloxacin (54.05\%), Cotrimoxazole (52.52\%),
Norfloxacin (51.35\%), Cefipime (51.35\%), Ceftazidime (50.45\%), Ceftriaxone (46.85\%), Cefotaxime (46.85\%). Nitrofurantoin showed a susceptibility of $37.84 \%$. Similar sensitivity pattern for Cephalosporins, Fluoroquinolones and Nitrofurantoin has been reported by Shah et al. (2015), Razak et al. (2012). 53.15\% of Klebsiella produced Extended Spectrum Beta Lactamase.

Table.1 Age Distribution

\begin{tabular}{|c|c|c|}
\hline $\begin{array}{c}\text { AGE GROUP } \\
\text { (in years) }\end{array}$ & $\begin{array}{c}\text { Number of patients } \\
\text { with UTI } \\
\text { (n=666) }\end{array}$ & Percentage \\
\hline \hline $0-10$ & 18 & 2.70 \\
\hline $11-20$ & 21 & 3.15 \\
\hline $21-30$ & 84 & 22.95 \\
\hline $31-40$ & 72 & 19.67 \\
\hline $41-50$ & 116 & 31.69 \\
\hline $51-60$ & 117 & 31.97 \\
\hline $61-70$ & 143 & 39.07 \\
\hline $71-80$ & 94 & 25.68 \\
\hline $81-90$ & 14 & 3.83 \\
\hline $91-100$ & 02 & 0.55 \\
\hline
\end{tabular}

Table.2 Bacterial Profile of UTI

\begin{tabular}{||c||c||c||}
\hline \multicolumn{1}{|c||}{ Bacteria isolated } & Number & Percentage \\
\hline \hline Escherichia coli & 360 & 57.14 \\
\hline Klebsiella species & 111 & 17.62 \\
\hline Enterococcus species & 51 & 8.1 \\
\hline Pseudomonas aeruginosa & 44 & 6.98 \\
\hline Staphylococcus species & 25 & 3.97 \\
\hline Acinetobacter species & 20 & 3.17 \\
\hline Citrobacter species & 07 & 1.11 \\
\hline Enterobacter species & 06 & 0.95 \\
\hline Proteus mirabilis & 05 & 0.79 \\
\hline Morganella morganii & 01 & 0.001 \\
\hline
\end{tabular}


Table.3 Antibiotic Sensitivity Pattern of Enterobacteriaceae (in percentage)

\begin{tabular}{|c||c|c|c|c|c|c||}
\hline & E.coli & Klebsiella & Citrobacter & Enterobacter & Proteus & Morganella \\
\hline \hline AK & 89.17 & 76.58 & 85.71 & 33.33 & 100 & 100 \\
\hline GEN & 60.83 & 57.66 & 71.43 & 33.33 & 80 & 100 \\
\hline CTR & 35.56 & 46.85 & 57.14 & 16.67 & 80 & 100 \\
\hline CTX & 35.56 & 46.85 & 57.14 & 16.67 & 80 & 100 \\
\hline CAZ & 37.78 & 50.45 & 57.14 & 16.67 & 80 & 100 \\
\hline CPM & 39.44 & 51.35 & 57.14 & 16.67 & 80 & 100 \\
\hline PIT & 78.33 & 66.67 & 71.43 & 33.33 & 100 & 100 \\
\hline IMP & 83.33 & 74.77 & 85.71 & 33.33 & 100 & 100 \\
\hline CIP & 28.33 & 54.05 & 57.14 & 16.67 & 100 & 100 \\
\hline NX & 27.5 & 51.35 & 57.14 & 16.67 & 80 & 100 \\
\hline COT & 38.06 & 52.52 & 42.86 & 16.67 & 20 & 100 \\
\hline NIT & 85.83 & 37.84 & 42.86 & 0 & 0 & 0 \\
\hline
\end{tabular}

Table.4 Antibiotic Sensitivity Pattern of Nonfermenters (in percentage)

\begin{tabular}{|c||c|c||}
\hline & Pseudomonas & Acinetobacter \\
\hline \hline AK & 45.45 & 45 \\
\hline GEN & 38.64 & 35 \\
\hline TOB & 31.82 & - \\
\hline CTR & - & 20 \\
\hline CTX & - & 20 \\
\hline CAZ & 31.82 & 25 \\
\hline CPM & 34.09 & 30 \\
\hline PIT & - & 35 \\
\hline PI & 38.64 & - \\
\hline IMP & 59.09 & 35 \\
\hline CIP & 25 & 30 \\
\hline NX & 13.64 & 30 \\
\hline COT & - & 45 \\
\hline
\end{tabular}

Table.5 Antibiotic Sensitivity Pattern of Gram Positive Bacteria (in percentage)

\begin{tabular}{|c|c|c|}
\hline & $\begin{array}{c}\text { Staphylococcus } \\
\text { Species }(\mathrm{n}=25)\end{array}$ & $\begin{array}{c}\text { Enterococcus } \\
\text { Species }(\mathrm{n}=51)\end{array}$ \\
\hline \hline P & 24 & 13.73 \\
\hline AMP & - & 74.51 \\
\hline CX & 76 & - \\
\hline CIP & 17.33 & 25.49 \\
\hline NX & 48 & 25.49 \\
\hline GEN & 72 & - \\
\hline HLG & - & 37.25 \\
\hline COT & 56 & - \\
\hline NIT & 80 & 82.35 \\
\hline TE & 72 & 43.14 \\
\hline VA & 100 & 100 \\
\hline LZ & 100 & 100 \\
\hline
\end{tabular}


Table.6 Overall Sensitivity of Commonly used Antibiotics for Gram Negative Bacteria

\begin{tabular}{||c|c||}
\hline Antibiotics & $\begin{array}{c}\text { Percentage of } \\
\text { sensitivity }\end{array}$ \\
\hline \hline AK & 71.9 \\
\hline PIT & 65.4 \\
\hline NIT & 53.61 \\
\hline COT & 46.4 \\
\hline CTR & 44.52 \\
\hline NX & 34.29 \\
\hline
\end{tabular}

Table.7 Antibiogram of Yeasts

\begin{tabular}{|l|l|}
\hline Antifungal agent & $\begin{array}{l}\text { Percentage } \\
\text { of sensitivity }\end{array}$ \\
\hline Amphotericin B & 94.4 \\
\hline Nystatin & 94.4 \\
\hline Clotrimazole & 91.64 \\
\hline Fluconazole & 88.89 \\
\hline Ketoconazole & 80.56 \\
\hline
\end{tabular}

Figure.1 Gender Distribution

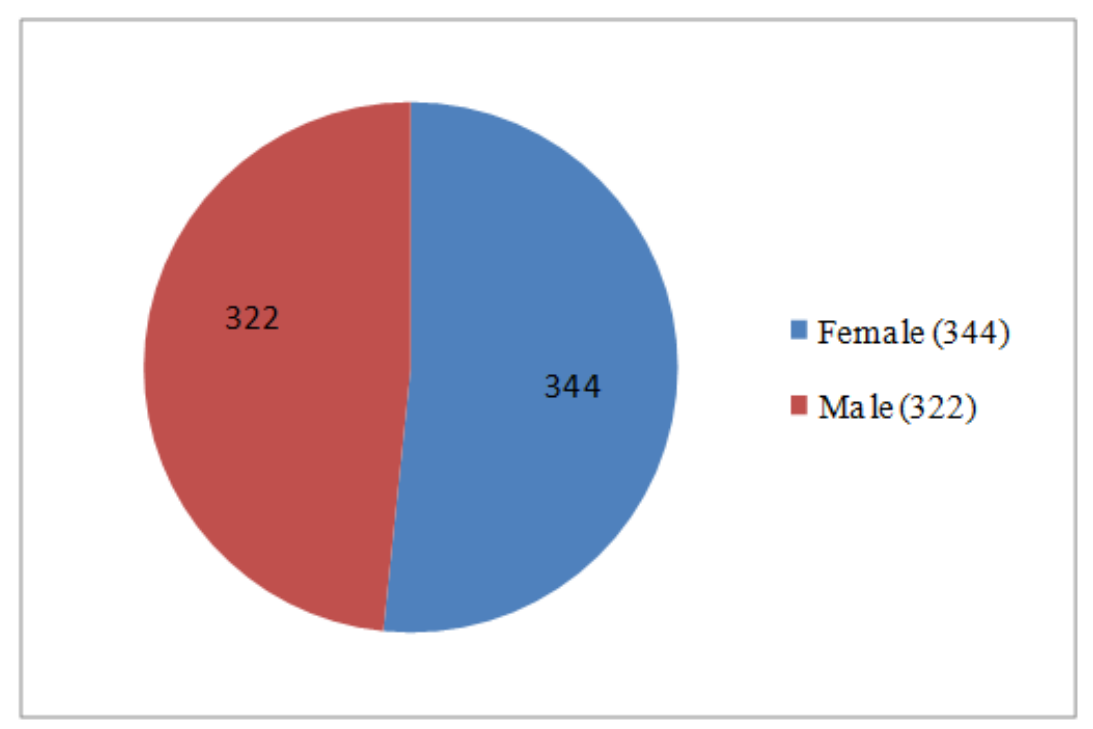


Figure.2 Age Distribution

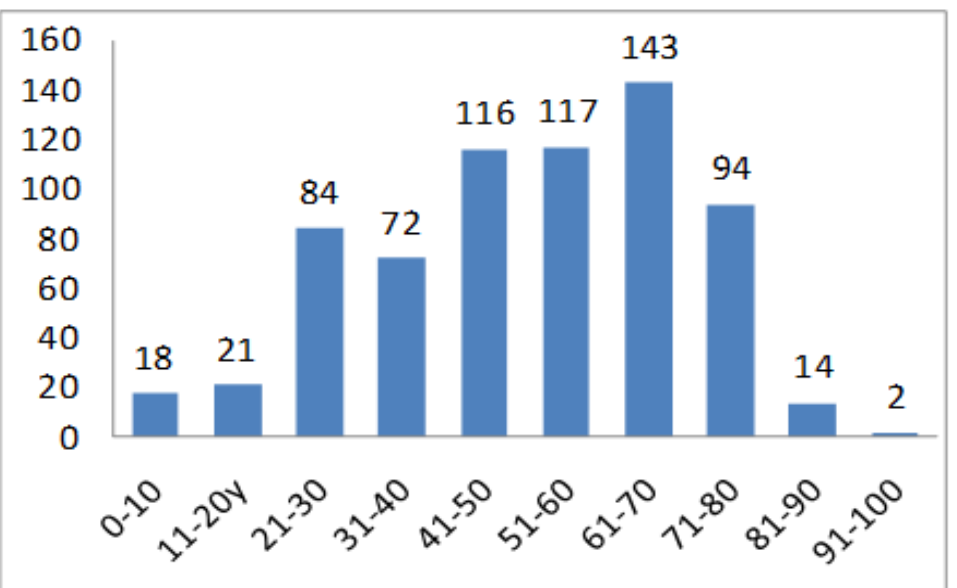

Figure.3 Distribution of Isolates

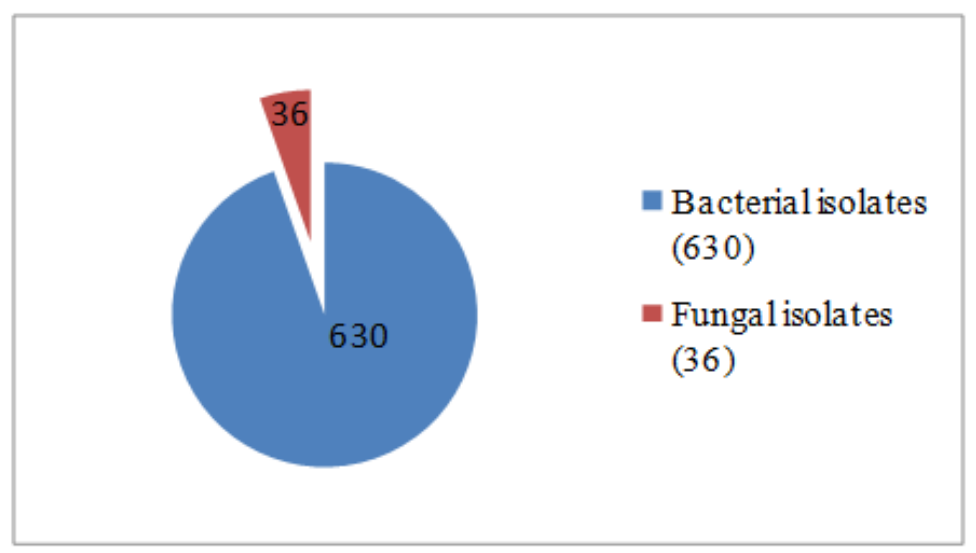

Figure.4 Bacterial Profile of UTI

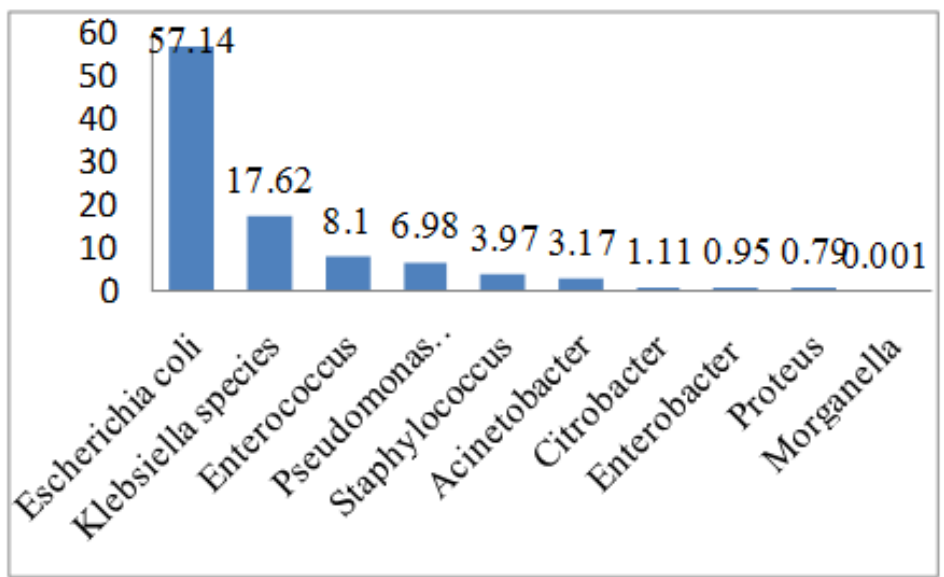


The present observed that Pseudomonas aeruginosa isolated in our study was mostly resistant to many of the antibiotics. Amikacin showed maximum sensitivity (45.45\%) followed by Gentamicin, Cefipime (34.09\%), Ceftazidime (31.82\%), Ciprofloxacin (25\%), Norfloxacin (13.64\%). Similar susceptibility pattern has been reported by Kulkarni et al. (2014).

Over $80 \%$ of P.mirabilis were sensitive to all the drugs tested except for cotrimoxazole which showed susceptibility of only $20 \%$. Only one Morganella morganii was isolated and it was susceptible to all the drugs tested except Nitrofurantoin. Staphylococcal species showed highest sensitivity to Vancomycin and Linezolid (100\%) followed by Nitrofurantoin (80\%), Gentamicin and Tetracycline (72\%), Cotrimoxazole (56\%), Norfloxacin (48\%). Least sensitivity was seen against Ciprofloxacin (17.33\%) and Penicillin (24\%). Six among 19 S.aureus were Methicillin resistant (31.58\%).

Candida showed maximum sensitivity to Amphotericin B and Nystatin (94.4\%) followed by Clotrimazole (91.64\%), Fluconazole (88.89\%) and Ketoconazole $(80.56 \%)$.

Our study showed a high prevalence of UTI in females and in the elderly patients. The increased prevalence in elderly could be attributed to co morbidities like diabetes mellitus. E.coli still remains the commonest causative agent for UTI with a high sensitivity rate to Nitrofurantoin. Most of the gram negative bacilli showed increasing rates of resistance to routinely tested and used antibiotics like Cephalosporins, Fluoroquinolones and Trimethoprimsulfamethoxazole.Though the resistance patterns in our study are similar to other studies, it is on the rise due to the uncontrolled abuse of the available antibiotics. Hence it becomes very essential to analyse the causative agent for UTI, establish antibiotic policies and take stringent measures to ensure effectiveness of the same. Failing to do so might result in the rise of multi drug resistant bacteria due to irrational use of antibiotics.

\section{References}

Alemu, A., Moges, F., Shiferaw, Y., Tafess, K., Kassu, A., Anagaw, B., Agegn, A. 2012. Bacterial profile and drug susceptibility pattern of urinary tract infection in pregnant women at university of Gondar Teaching hospital, Northwest Ethiopia. BMC Res. Notes, 5(97): 1-7.

Ampaire, L., Butoto, A., Orikiriza, P., Muhwezi, O. 2015. Bacterial and Drug Susceptibility Profiles of Urinary Tract Infection in Diabetes Mellitus Patients at Mbarara Regional Referral Hospital, Uganda. British Microbiol. Res. J., 9(4): 1-5.

Ananthanarayan, R., Paniker, C.K.J. 2009. Hospital Infection. In: Paniker CKJ, editor. Ananthanarayan and Paniker's Textbook of Microbiology, $8^{\text {th }}$ ed. Hyderabad: Universities Press (India) Private Limited, pp. 623-627.

CLSI. 2013. Performance Standards for Antimicrobial Susceptibility Testing; Twenty-Fourth Informational Supplement. CLSI document M100S24. Wayne, PA: Clinical and Laboratory Standards Institute.

Collee, J.G., Miles, R.S., Watt, B. 2014. Tests for the identification of bacteria. In: Collee JG, editor. Mackie \& McCartney Practical Medical Microbiology, 14th ed. New Delhi: Elsevier, pp.131-150.

Eshwarappa, M., Dosegowda, R., Aprameya, I.V., Khan, M.W., Kumar, P.S., Kempegowda, P. 2011. Clinico- 
microbiological profile of urinary tract infection in south India. Indian $J$. Nephrol., 21(1): 30-36.

Hussein, N.S. 2014. Clinical, Etiology and Antibiotic Susceptibility Profiles of Community- Acquired Urinary Tract Infection in a Baghdad Hospital. Med. Surgical Urol., 3(2): 1-5.

Janifer, J., Geethalakshmi, S., Satyavani, K., Viswanathan, V. 2009. Prevalence of lower urinary tract infection in South Indian type 2 diabetic subjects. Ind. $J$. Nephrol., 19(3): 107-111.

Jitendranath, A., Radhika, R., Bhargavi, L., Bhai, G., Beevi, R. 2015. Microbiological Profile of Urinary Tract Infection in Pediatric Population from a Tertiary Care Hospital in South Kerala. J. Bacteriol. Mycol., Open Access. 1(1): 1-5.

Kulkarni, S.G., Talib, S.H., Naik, M., Kale, A. 2014. Profile of Urinary Tract Infection in Indwelling Catheterized Patients. IOSR J. Dent. Med. Sci., 13(4): 132-38.

Orhue, P.O. 2014. Prevalence of uropathogenic bacterial isolates from urinary tract infections: A case study of university of Benin teaching hospital, Benin City, Nigeria. Int. J. Microbiol. Appl., 1(2): 18-22.
Patel, P., Garala, R.N. 2014. Bacteriological profile and antibiotic susceptibility pattern (antibiogram) of urinary tract infections in paediatric patients. $J$. Res. Med. Dent. Sci., 2(1): 20-23.

Razak, S.K., Gurushantappa, V. 2012. Bacteriology of Urinary Tract Infection and Antibiotic Susceptibility Pattern in a Tertiary Care Hospital in South India. Int. J. Med. Sci. Public Health, 1(2): 109-112.

Shah, L.J., Vaghelam, G.M., Mahida, H. 2015. Urinary tract infection: Bacteriological profile and its antibiotic susceptibility in western India. Nat. J. Med. Res., 5(1): 71-74.

Sharma, A., Shrestha, S., Upadhyay, S., Rijal, P. 2011. Clinical and Bacteriological profile of urinary tract infection in children at Nepal Medical College Teaching Hospital. Nepal Med. Coll. J., 13(1): 24-26.

Sibi, G., Devi, A.P., Fouzia, K., Patil, B.R. 2011. Pravalence, Microbiologic profile of urinary tract infection and its treatment with Trimethoprim in Diabetic patients. Res. J. Microbiol., 6(6): 543-551.

\section{How to cite this article:}

Preethishree, P., Rekha Rai, K. Vimal Kumar, K.B. Asha Pai and Pratibha Bhat U. 2016. Uropathogens and their antibiotic susceptibility pattern at a tertiary care teaching hospital in Coastal Karnataka, India. Int.J.Curr.Microbiol.App.Sci. 5(1): 23-31. doi: http://dx.doi.org/10.20546/ijcmas.2016.501.003 